\title{
Discurso do sujeito coletivo, complexidade e auto-organização
}

\section{Discourse of the collective subject, complexity and self-organization}

Fernando Lefevre ${ }^{1}$

Ana M aria Cavalcanti Lefevre ${ }^{2}$

$M$ aria Cristina da Costa $M$ arques ${ }^{1}$

Abstract The aim of the present work is to discuss some consequences of the method called "Discourse of the Collective Subject" concerning the semantic density of the qualitative data, that implies a significantly and more relevant presence of the collective thought as empirical reality in qualitative researches. Such a presence of the empirical material, associated to the understanding of the collective thought as referent, allows a dialogue of the descriptive and interpretative moment in this variety of research. This in turn alludes to a new possibility that points out to the uncertain and unexpected contributing to a renewed understanding of the nature and processes of the social representations as complex realities. Key words Discourse of the collective subject, Complexity, Collective thought, Self-organization
Resumo 0 presente trabalho busca apresentar alguns desdobramentos do método do discurso do sujeito col etivo no que toca à densidade semântica por ele provocada, que implica a presença significativamente mais relevante, nas pesquisas sociais que envolvam coleta de depoimentos, do pensamento coletivo como realidade empírica. Tal presença mais significativa do material empírico, aliada ao entendimento do pensamento das coletividades como re ferente, permite 0 diálogo do momento descritivo com o momento interpretativo neste tipo de pesquisa, podendo assim, como nova possibilidade que aponta para o incerto e para o inesperado, contribuir para um entendimento renovado da natureza edo funcionamento das representações sociais como realidades complexas.

Palavras-chave Discurso do sujeito coletivo, Complexidade, Pensamento coletivo, Auto-organização

\footnotetext{
${ }^{1}$ Departamento dePrática deSaudePública, Faculdade deSaúdePública,

U niversidadedeSão Paulo.

Av. Dr. Arnaldo 71,

Cerqueira Cesar.

01246-000 São Paulo SP. flefevre@usp.br

${ }^{2}$ Instituto de Pesquisa do

Discurso do Sujeito

Coletivo.
} 


\section{Introdução}

A experiência demais de dez anos com a produção própria de trabalhos usando o discurso do sujeito coletivo ou DSC ${ }^{1}$ e com a análise ou acompanhamento de projetos de outros pesquisadores que utilizam o DSC tem nos dado a certeza de que esta metodologia gera um novo tipo de resultado sobre o qual é preciso refletir.

0 tema do presente trabalho é a exploração das implicações da idéia contemporânea de complexidade nas suas relações com o discurso do sujeito coletivo enquanto proposta metodológica para pesquisas sociais que buscam descrever e interpretar representações sociais.

Não vamos detalhar aqui a metodologia; diremos apenas, muito sinteticamente, que o discurso do sujeito coletivo, como técnica de processamento de depoimentos, consiste em reunir, em pesquisas sociais empíricas, sob a forma de discursos únicos redigidos na primeira pessoa do singular, conteúdos de depoimentos com sentidos semelhantes.

Estes conteúdos de mesmo sentido, reunidos num único discurso, por estarem redigidosna primeira pessoa do singular, buscam produzir no leitor um efeito de "coletividadefalando"; além disso, dão lugar a um acréscimo de densidade semântica nas representações sociais, fazendo com que uma idéia ou posicionamento dos depoentes apareça de modo "encorpado", desenvolvido, enriquecido, desdobrado.

No que toca às representações sociais, podemos dizer, em paralelo, que há por certo uma quaseinevitável flutuação ou imprecisão terminológica em trabalhos como o presente. Por isso, vale salientar que utilizaremos o conceito de representação social, aqui, como o equivalente dos substratos verbais ou verbo-narrativos das representações, deixando claro portanto que essas repre sentações são fenômenos complexos que extrapolam largamente suas manifestações verbais.

Retomando o fio desta introdução, podemos começar a enunciar nossa tese central dizendo que o DSC, como método, porque gera representações sociais "encorpadas", com grande volume de conteúdo, implica em termos semióticos, a val orização da dimensão sintagmática das representações (Iigada ao conteúdo destas, ou, na terminologia do DSC, às expressões-chave). Por outro lado, este mesmo conteúdo "encorpado" reforça a dimensão paradigmática das representações, isto é, a identificação e nomeação de conjuntos de depoimentos com sentido semelhante, bem como a distinção entresi dos conjuntosque, naterminologia do DSC, apresentam diferentesidéias centrais ou ancoragens.
Em paralelo, apenas a título de esclarecimento, diremos que, para a semiologia ou semiótica enquanto ciência geral dos processos de significação, a dimensão sintagmática (a do e/e) refere-se relações entre si dos elementos constitutivos dos discursos ou enunciados, enquanto a dimensão paradigmática (a do ou/ou), a da escolha de cada elemento do enunciado dentre um rol de escolhas possíveis.

Enfatizando a dimensão sintagmática das representações (a do e/e), colocaremos que sua valorização permite tornar as representações mais ricas e mais claras, porque mais exemplificadas, mais detalhadas, mais justificadas.

Ora, isso vai levar a um aumento físico e espacial da presença empírica da representação na pesquisa social quetem depoimentos como sua matéria-prima, o que implica também um aumento do status desta dimensão empírica frente à dimensão teórica ou metadiscursiva, neste tipo de pesquisa.

Temos com isso um acréscimo do poder explicativo da representação?

Sem dúvida uma representação mais ricamente descrita, mais detalhada, mais justificada permitiria entender melhor aquilo queas pessoas pensam sobre um dado tema. M as por que isso significaria um aumento do poder explicativo da representação?

Porque, não sendo a representação o que as pessoas pensam, mas o signo ou a manifestação, ou tradução verbal e também discursiva e narrativa do que as pessoas pensam, uma representação mais ricamente descrita vê aumentado o poder explicativo sobreseu objeto - que, em termos peirceanos, corresponderia ao "objeto do signo"2 ou 0 referente da representação.

\section{Complexidade}

Para avançar no entendimento de nosso tema, enunciado acima, pareceútil contextualizá-lo ereferi-lo teoricamenteà idéia de complexidade.

Por que tal escolha?

Porque, como se verá a seguir, o discurso do sujeito coletivo, pelas suas características, abre, no que toca às representações sociais como objeto de pesquisa empírica, novas possibilidades de relações - no caso de diálogo - entre o todo e as partes, entreo individual eo coletivo, entreo teórico e o empírico, entre a descrição e a interpretação, entre a síntese e a análise, entre o paradigma e o sintagma e, last but not least, entre 0 qualitativo e 0 quantitativo, o que justifica, e talvez exija, a sua inserção no quadro das reflexões atuais sobre 0 tema da complexidade. 
Nesse sentido valeria, cremos, uma breve exposição sobre a idéia de complexidade, sem qualquer pretensão outra que não seja a de situá-la enquanto pano defundo teórico subjacenteà problemática diretamente abordada aqui, que diz respeito aos possíveis efeitos do DSC (como modo de processar depoimentos) no sentido das representações sociais que emergem de pesquisas sociais empíricas.

A complexidade, como conceito nuclear, vem sendo abordada na ciência contemporânea como fundamental para a compreensão de fenômenos em diversos campos do conhecimento. 0 pressuposto da complexidade aponta para o reconhecimento de que a simplificação obscurece as interrelações de fato existentes entre todos os fenômenos do universo e que é imprescindível ver e lidar com a complexidade do mundo em todos os seus níveis.

A idéia de "complexidade" ou "complexo" está ligada, no cotidiano dos discursos, a "complicado", à idéia da dificuldade explicativa para fatos, realidades, problemas. Tal dificuldade explicativa se refere comumente à diversi dade de fatores e as implicações entre eles. Algo é complexo quando é difícil de explicar, ou seja, quando não é simples.

$N$ ão obstante, a origem da palavra, do latim complexus, diz respeito ao que "abrangeou encerra muitos elementos ou partes", ou ainda, ao "conjunto de coisas, fatos ou circunstâncias que têm qualquer ligação ou nexo entre si". Ainda, segundo Aleksandrowicz ${ }^{3}$, complexidade deriva de vocábuIo latino, significando "entrelaçado, abraçado, contido", tendo, na língua portuguesa, adicionado ao seu sentido literal de "intrincamento de circunstâncias" uma nuance de dificuldade.

A ênfase na complexidade como conceito explicativo para os fenômenos da vida em seus diversos aspectos acentua-se, entretanto, a partir do início do século $X X$, quando novos empregos do termo são utilizados e estudados, no campo da matemática (números complexos, al goritmos não simplificados), da química (corpos ou substâncias com elementos diferentes ou heterogêneos são reconhecidos como associados), nos modelos da cibernética, nas teorias da informação e da comunicação, na psicanálisee, atualmente, nas reflexões da antropologia moderna e nas ciências sociais4.

Pensadores como Edgar M orin, Henry Atlan, M aturana, Varela, M ichel Serres, entreoutros, contribuíram de forma decisiva nas últimas décadas para a construção da idéia de complexidade e seus modelos apontam principalmente para a necessidade da interação entre sistemas, sem perder 0 potencial da diversidade. Silva ${ }^{5}$, apontando para
M orin, reflete sobrea complexidade como sendo a estratégia da desintegração para a reconstrução, "a complexidade desmonta a totalidade clássica e monolítica, com a preocupação teórica de estabelecer uma nova totalidade aberta, circular, precária e em permanente intercâmbio com as suas partes".

Assim, o todo não mais se constitui como soma das partes, mas pela interação que se dá entre elas. A explicação complexa está ligada não mais ao reconhecimento do conteúdo das partes (dos seres vivos, por exemplo) mas, somado a este reconhecimento, a inter-relação que se dá internamente nessesistema e externamente com o ambiente. Este princípio da complexidade alimentará inúmeros trabalhos relativos à reflexão sobre os sistemas culturais e societais, nas suas relações internas e com a sociedade.

Entender os fenômenos da vida na sociedade pressupõe, segundo o pensamento complexo, contextualizar estes fenômenos na sua relação com o todo (a sociedade) e com os sistemas singulares de sua existência. A complexidade vai dialogar deperto com a incerteza e com o acaso, sendo, por essa razão, resistente aos modelos explicativos simplificadores e cartesianos que pretendem, através de determinismos calcificados no positivismo, explicar os fenômenos da vida. A rede causal é circular e dinâmica, amparada nos conceitos de ordem, desordem e auto-organização. Não significa, entretanto, segundo autores como Atlan ${ }^{6}$, negar o determinismo e as leis que estão presentes nos fenômenos naturais, por exemplo, mas apontar para o al eatório, o ocaso, o ruído, que, ao contrário do significado para a comunicação, pode ser positivado como propiciadores de novas formas de resposta e organização social.

A noção de ruído vem da teoria das comunicações de Shannon, que aguçadamente utiliza deste conceito para construir a teoria da complexidade pelo ruído. Na comunicação, ruídos são erros na transmissão de mensagens e indesejáveis em uma comunicação, motivo pelo qual, na teoria da comunicação, não existe positividade na presença de ruídos. No caso dos sistemas naturais, este evento pode ser diferente. Os sistemas naturais criam vias alternativas de comunicação na ocorrência de ruídos, tornando-se mais complexos. N esta direção, a complexidade pelo ruído poderia explicar a comunicação entre sistemas sociais que na presença de ruídos (aqui entendidos como fenômenos naturais, sociais, entre outros) se complexificam para criar novas formas de organização e sobrevivência.

Alecsandrovics ${ }^{3}$, referindo o pensamento deAtlan sobre a complexidade e sua discussão sobre autoorganização, aponta também para a distinção que 
este autor faz entre racionalidade científica e racionalidade mítica. A racionalidade científica pretende um controle da realidade concreta por meio da técnica, por sua vez, a racionalidade mítica éa que explica os aspectos da existência no plano dos desejos evalores, desta forma criando também a ética, conforme vivida pela maioria dos indivíduos e grupos sociais.

$\mathrm{Na}$ reflexão sobre esta questão, 0 autor evidencia que as experiências de dor ede prazer decada um são memorizadas em função de sua história individual e coletiva e, sob efeito da memória e da imaginação, o bem eo mal associados às experiências sensoriais presentes são estendidos na duração e deslocados no espaço. N esta direção, podemos atribuir ao outro as mesmas experiências que as nossas, concebendo um bem ou um mal coletivos, re lativizados na forma de sublimar desejo e sofrimento de cada grupo humano.

A complexidade, como foi assinalado, pressupõe comunicação e interação entre as partes do sistema e o todo. A comunicação estabelece a possibilidade de sobrevivência eauto-organização dos sistemas complexos, como as comunidades humanas. Alguns parâmetros podem apontar o movimento de complexidade de um sistema segundo Parreira7: o nível de informação utilizado pelo sistema nas suas decisões de ação, o grau de variedade interna do sistema, ou seja, a diversidade das suas partes ou componentes, no plano cultural, socioemocional e estrutural, o grau de variedade externa do sistema, o número de entidades cultural e estruturalmente diferentes que interagem de forma permanente e o grau de exposição da variedadeinterna eexterna, expresso em decisões eações que efetivamente dela resultam e a aproveitam.

Assim sendo, pode-se colocar que ciência e a pesquisa, munidas da intuição sobre complexidade, estariam convergindo para a solução de questões a respeito de um mundo não mais fragmentado e estratificado, mas complexo e que exige, portanto, soluções também complexas.

Em conformidade como o referencial acima exposto, optou-se por segmentar em níveis a temática aqui discutida, para com isso poder revelar mais claramentea complexidadeinerenteseja às relações intra-partes, seja às relações inter-partes, nas pesquisas de representação social que usam o DSC.

Antes, porém, de entrar, em nível analítico, no detalhamento de cada uma das partes de nosso argumento central, que busca indicar as possíveis relações entre o DSC e a idéia de complexidade, convém, sinteticamente, enunciar nossa tese, nestes termos:

As representações sociais são esquemas sociocognitivos de que as pessoas lançam mão para emitirem, no cotidiano de suas vidas, juízos ou opiniões, que são condições necessárias para viver e se comunicar em sociedades complexas.

Estes esquemas sociocognitivos, acessáveis através de depoimentos individuais, são entidades virtuaisque, por isso, precisam ser reconstituídas através de pesquisas sociais que comportem uma dimensão qualitativa e quantitativa.

Tais pesquisas revelam um primeiro nível de complexidade do fenômeno das representações sociais, que se traduz na constatação que o estudo eo entendimento do pensamento coletivo implica uma démarche complexa, na medida em que diz respeito à articulação entre 0 virtual, ou seja, os esquemas, o individual, ou seja, os depoimentos e o coletivo, isto é, o uso destes esquemas internalizados nas interações e comunicações sociais.

O segundo nível, mais interno, de complexidade da problemática aqui discutida é dado pela produção propriamente dita, nas pesquisas que usam o DSC, das representações como painéis dediscursos coletivos.

0 presentenível encerraumaproblemática complexa na medida em que revela a presença ea necessária articulação teórico-metodológica entre o nível anterior, mais teórico, cuja principal tarefa consiste na "desvirtualização" das representações sociais e este segundo nível mais propriamente metodológico, que implica um encadeamento de operações que envolve a transformação do depoimento bruto em depoimento trabalhado, identificação do sentido ou sentidos de cada depoimento, categorização, ou seja, agrupamentos de depoimentos semelhantes em conjuntos, denominação destes conjuntos, reunião de conteúdos de depoimentos semelhantes num depoimento único, entre outras.

0 terceiro nível de complexidade diz respeito às relações entre este substrato empírico constituído pelo painel deDSC squeexpressam, descritivamente, as representações sociais e o metadiscurso teórico do pesquisador na sua tarefa de interpretação dos dados.

Reunindo-se estas três "complexidades", postula-se que a novidade do DSC, pela grande importância que tal pesquisa confere aos discursos das representações sociais como fenômeno empírico com alto poder de auto-organização, consiste em que, nesta metodologia, as relações entre descrição e interpretação, entre discurso e metadiscurso na pesquisa do pensamento coletivo devem ser muito mais horizontais, ou seja, de diálogo, do que costuma acontecer normalmente, em que 0 mundo empírico aparece demasiadamente subordinado ao metadiscurso teórico (digamos arrogante) do pesquisador. 
Podemos agora detalhar analiticamente estas "complexidades".

\section{Complexidade nível I: produção individual das representações sociais}

Esquematicamente, o que se busca colocar neste nível éque:

- As pessoas pensam ou são capazes de pensar sobre temas que lhes digam respeito (até como condição básica da sua existência como seres sociais ou, como diriam os gregos, como animais políticos);

- As pessoas pensam com base em representações sociais, existentes (da perspectiva da pesquisa social empírica) em forma virtual na sociedade. Do ponto de vista da pesquisa social empírica, isso não significa dizer, evidentemente, que as representações sociais não sejam entidades concretas e nada virtuais: noticiários de TV, artigos de jornais ou revistas, conversas de botequim ou cabeleireiro, entre tantos outros textos, são exemplos de uma infinidade de oportunidades dos indivíduos receberem informações com as quais compõe as suas representações sociais. $M$ as, parece-nos, tais informações, em si, não constituem exatamente representações sociais mas, mais apropriadamente, fontes de representações sociais: para se tornarem e, mais ainda, para funcionarem, efetivamente, como representações sociais, el as precisam passar pelo filtro das consciências individuais;

Detal hando o esquematizado acima, diríamos inicialmenteque parece constituir constatação primária colocar que uma coletividade de pessoas, sobre temas que são capazes de pensar, pensam algo (nossa experiência empírica sugere, todavia, que, pelo menos entre nós, brasileiros, as pessoas podem pensar ou opinar também sobre assuntos que, em tese, não seriam, por não serem técnicos no assunto, capazes de opinar).

M as, evidentemente, apesar da primariedade desta constatação, há todo um arcabouço teóricometodológico prévio, que, a nosso ver, permite construir esta primariedade como uma questão de pesquisa, ou seja, que viabiliza a construção da opinião coletiva como um objeto a ser pesquisado e acessado de modo cientificamente válido.

Faz parte deste arcabouço teórico pensar as opiniões coletivas como representações coletivas ou sociais ${ }^{8}$, habitus ${ }^{9}$, ideologias, crenças, sistemas simbólicos que, considerando as coisas esquematicamente, podem ser vistas como matrizes discursivas existentes nas formações sociais, às quais os indivíduos se reportam, para emitirem seus juízos pessoais.
Estas matrizes, por sua vez, existem, mas apenas como potencialidades quesó adquirem formaeconsistência como representações sociais através da sua metabolização pelas consciências individuais.

Para que este produto das consciências individuais setransformeem representação social, é preciso pensar tal produto como um texto ou discurso narrativo, que veicula um dado posicionamento diante do tema pesquisado.

A representação precisa ser um texto deste tipo porque só o texto narrativo - e nunca partes de texto (palavras, por exemplo) - permite veicular um ou mais sentidos, que revelam posicionamentos ou opiniões.

É preciso finalmente pensar que estes textos dependem do recorte do tema por meio de perguntas estrategicamente compostas, de modo a fazer com que as respostas dos indivíduos constituam o melhor acesso possível às representações sociais.

Podemos chamar toda esta etapa do processo de complexidade nível I porque envolve uma articulação entre 0 virtual, 0 individual e o coletivo, uma vez que se trata de representações sociais resultantes de internalizações externalizadas e socializadas nas interações sociais cotidianas, que reproduzem e atualizam representações existentes virtualmente na sociedade.

Todo este processo tem, neste nível, como output maior, a produção deuma matéria-prima (conjunto de depoimentos de pessoas) de qualidade para a pesquisa de representação social.

Tal output aparece então como input para a etapa seguinte, que se detalha abaixo.

Complexidade nível II: re-produção coletiva das representaçõessociais

O segundo nível nas pesquisas com o DSC, o do processamento da matéria-prima dos depoimentos, permitiráqueseimplemente a respeito do tema $X$, os discursos que revelam o que as coletividades pensam, como pensam o que pensam e como este pensamento se distribui no espaço social.

$\mathrm{N}$ a técnica do $\mathrm{DSC}^{1}$, a matéria-prima produzida na etapa denominada complexidade nível I é, agora, na denominada complexidade nível II, me todologicamente tratada com vistas à produção propriamente dita do pensamento coletivo sob a forma de um painel de DSCs, selecionando-se as expressões-chave das respostas individuais e identificando-se a ou as idéias centrais e/ou ancoragens correspondentes. Em seguida, as respostas individuais, assim tratadas, são reunidas a outras 
respostas que apresentam sentidos semel hantes ou complementares, consubstanciando um depoimento síntese. 0 conteúdo deste depoimento sínteseé, por sua vez, editado, com o uso de uma série de técnicas para constituir o produto final que éo discurso do sujeito coletivo, ou seja, uma opinião coletiva de uma pessoa coletiva, redigida na primeira pessoa do singular.

Finalmente, as representações sociais sobre 0 assunto pesquisado, ou mais precisamente, seu substrato discursivo, são constituídas pelo conjunto dos discursos do sujeito coletivo relativos aos temas e subtemas pesquisados.

Esta complexidade nível II revela a necessidade, para se configurar as opiniões coletivas, de por em prática um grande número de operações encadeadas queculminam no painel de discursos coletivos.

Com efeito, o processamento das respostas que culmina na produção dos discursos do sujeito coletivo supõe: uma postura rigorosamente descritiva, a análise detalhada, a seleção do conteúdo relevante de cada resposta, a busca e a nomeação do(s) sentido(s) manifesto(s) (as idéias centrais) e latentes (as ancoragens) presentesnos conteúdos das respostas e, finalmente, a edição dos DSCs, condições necessárias para que as pesquisas com o DSC sejam vistas como produções da ciênciaque possam, como todo pensamento científico, ser criticadas nas suas eventuais insuficiências ou erros e reproduzidas pelos pesquisadores que assim o desejarem.

\section{Pressuposto teórico-metodológico}

A soma destas duas complexidades pressupõe um modelo sobreo queéo pensamento coletivo e uma metodologia destinada, através de pesquisas empíricas, a fazer emergir pensamentos coletivos sobre temas específicos, que sejam conformes a este modelo.

Tal modelo/metodologia, esquematicamente, postula que :

Os pensamentos coletivos ou representações sociais são metabolizações pessoais ou individuais de matrizes discursivas existentes virtualmentenas formações sociais, acessadas através de pesquisas com indivíduos questionados através de perguntas abertas, metabolizações essas que, visando à atualização e expressão concreta, em forma de opiniões coletivas, das matrizes discursivas virtuais, são, sob a forma de constructos, agrupadas, por semel hança semântica, em discursos síntese redigidos na primeira pessoa do singular, de modo a configurar um sujeito coletivo portador de uma opinião, ou de um "eu acho..." social.
De fato, um dos testes para saber se tal modelo/metodologia foi de fato implementado numa dada pesquisa concreta consiste em verificar se sujeitos entrevistados numa pesquisa que utiliza o DSC, colocados diante dos discursos do sujeito coletivo que ajudaram a constituir, são, efetivamente capazes de se identificar com o mesmo e dizer: "eu também acho tudo isso!" Temos experiências concretas de "devoluções" de resultados de pesquisas feitas com o DSC nas quais tal sentimento foi diversas vezes manifestado por participantes das "devolutivas". Foi o caso de trabalho que desenvolvemos em Itapecerica da Serra, São Paul ${ }^{10}$, envolven do avaliação de um programa de humanização do atendimento de saúde, e no Rio de Janeiro ${ }^{11}$, envolvendo avaliação da implantação um processo de vigilância à saúde com os funcionários da Secretaria da Saúde deste estado.

Este sujeito coletivo pessoal ou pessoalizado e seu discurso constituem, acredita-se, uma forma mais viva e mais "natural" de reconstrução e expressão das representações sociais, porque mais "encarnada" em sujeitos. E isso porque se acredita, conforme explicitado na sessão "Complexidade nível I", que é pela via das pessoas, que são seus portadores, que as representações sociais funcionam, na prática, no dia-a-dia das interações sociais da vida cotidiana.

\section{Complexidade nível III : ressignificação interpretativa das representações sociais ou a emergência do diálogo}

0 terceiro nível - o que classicamenteé apresentado nos relatórios ou nos papers sob a rubrica "Discussão einterpretação dos dados" - diz respeito às perguntas: o que, do dado bruto das opiniões sob a forma de DSCs, pode ser destacado; por que as pessoas pensam o que pensam; qual o contexto destepensamento; quais suas consequências equais suas implicações práticas.

Aqui, o lugar do sujeito da produção de sentido das representações sociais muda de dono (o dono anterior era o sujeito empírico, o que produz o discurso da realidade) passando a ser ocupado, de modo explicito, pelo pesquisador-portador-da-teoria ou do discurso sobre a realidade, ainda que, num primeiro momento (o da limpeza dos dados brutos), este pesquisador não esteja propriamente convocando um outro discurso, mas apenas desenvolvendo um rearranjo interno das informações.

$M$ as, da perspectiva do DSC - no qual o material empírico dos discursos individuais e coletivos das pessoas ganha um grande destaque - convocar 
outros textos para a tarefa explicativa, interpretativa, contextualizadora das representações sociais resultantes da pesquisa, que consiste, como diria Althusser ${ }^{12}$, em praticar teoria, vai implicar, da parte do pesquisador portador do metadiscurso teóri$\mathrm{co}$, a necessidade de dialogar, o tempo todo, com 0 texto empírico, buscando, sempre, tornar a explicação, a contextualização, as consequências e as implicações, compatíveis com este texto empírico.

O diálogo do discurso com o metadiscurso, na perspectiva que aqui se defende, é, portanto, muito diferente do habitual regime de relações existenteentreestes dois discursos na pesquisa social qualitativa tradicional, caracterizado pela dominação do discurso teórico sobre o empírico, que, no mais das vezes, se apresenta fragmentado, justaposto, esparso, funcionando sobretudo como ilustração e justificação para os posicionamentos teóricos do pesquisador.

$\mathrm{Na}$ pesquisa tradicional, o material empírico dos pensamentos coletivos não é, como no DSC, um discurso coletivo completo (com categoria, conteúdo, argumentos) mas, sempre, um composto de pedaços, fragmentos, nomes de discurso sem discurso (no caso das pesquisas com perguntas abertas apenas categorizadas) que, por isso, precisariam ser "completados" pelo "único discurso" que, segundo esta visão e segundo a prática dela decorrente, pode imperar na pesquisa, que é o metadiscurso teórico sobre a realidade, produzido pelo pesquisador.

Ora, é fácil ver por aí a porta aberta para a arbitrariedade ou para a violência simbólica ${ }^{13} \mathrm{da}$ tarefa explicativa, que no fundo não está sendo efetivamente mobilizada para explicar a realidade mas para "auto-explicar" e reproduzir a própria teoria.

Com o diálogo do empírico com o não empírico, proposto pelo DSC, temos de fato dois discursos sendo confrontados e, consequentemente, duas explicações: de um lado, o discurso empírico das opiniões ou representações sociais, sob a forma de um painel de discursos do sujeito coletivo que, como se assinalou no início, é um signo e, consequentemente, uma materialidade ou concretude que, enquanto fato simbólico e sociológico, dá sentido e luz ao referente; de outro lado, temos outro discurso, com outro sujeito (o pesquisadorportador-da-teoria), que é o discurso do contexto, que de fato funciona aqui como um com-texto, ou seja, como um texto com outro texto.
Ora, como temos dois discursos em diálogo, 0 segundo discurso, o do pesquisador/contexto não está explicando o primeiro, o discurso empírico da representação social: ambos estão explicando o referente, isto é, em termos peirceanos, o objeto do signo.

Cada DSC e o conjunto de DSC s que veiculam as representações sociais conformam opiniões coletivas completas e densas que, por isso, sugerem, incitam, estimulam a presença de outros discursos (da teoria, do contexto, das implicações) com os quais os DSCs podem, em condições de igual dade discursiva, conversar, dialogar e deste diálogo resultar um avanço no conhecimento apontando, talvez, para resultantes semânticas inéditas e inesperadas.

\section{Umailustração}

Apresentaremos abaixo um exemplo de um proje to desenvolvido com o DSC que permite ilustrar alguns aspectos da problemática aqui discutida.

Trata-se de uma pesquisa desenvolvida no ano de $2002^{14}$ por solicitação do M inistério da Saúde da Argentina, em parceria com a Organização PanAmericana da Saúde por ocasião da introdução pelo governo daquele país da política pública que exigia do médico a prescrição de medicamentos exclusivamente pelo nomegenérico. Os dados aqui apresentados referem-se à primeira etapa da pesquisa e foram coletados junto a usuários e médicos de hospitais públicos de Buenos Aires (Quadro 1 e Gráfico 1).

Vamos apresentar uma das perguntas que tem como tema a relação entre qualidade e preço dos medicamentos.

Pergunta:

H oje na Argentina os médicos devem receitar preferencialmente pelo nome genérico e não pela marca do medicamento. Isto significa que o paciente poderá escolher os medicamentos entre as diferentes opções de preços disponíveis. A pergunta é: o/a senhor/a considera que medicamentos de preços diferentes podem ter a mesma qualidade?

( $H$ oy en la Argentina los médicos deben recetar preferentemente por el nombre genérico y no por la marca del medicamento. Esto significa que el paciente podrá elegir entre distintas opciones de precios en losmedicamentos disponibles. La pregunta es: ¿U d. considera que medicamentos de distinto precio pue den tener la misma calidad?) 
Quadro 1. Síntese qualitativa das representações sociais.

\begin{tabular}{|l|}
\hline Categorias idéias centrais \\
SIM \\
A Porque os medicamentos podem ter preços diferentes, uma vez que o preço é determinado por vários \\
fatores que não têm necessariamente a ver com a qualidade do medicamento \\
B Porque a prescrição pelo nome genérico facilita o acesso da população aos medicamentos e também \\
permite ao consumidor a escolha da marca \\
C Porque confia nos órgãos governamentais, na seriedade dos laboratórios e nos médicos \\
D Desde o momento em que o Estado estabeleça controles, legislação e mecanismos de competição \\
adequados \\
COM RESERVAS \\
E Porque tem dúvidas sobre os mecanismos de controle de qualidade usados pelos laboratórios e farmácias \\
(controle de qualidade dos produtos feito pelas próprias empresas) \\
F Na atualidade, na Argentina, não há como garantir o controle de qualidade dos medicamentos pelo \\
Estado \\
NÃO \\
G Porque a qualidade de um medicamento depende de seu processamento. Os medicamentos de preço mais \\
baixo podem ter pior qualidade e os efeitos podem ser diferentes \\
H Porque quem deve indicar e informar ao paciente qual o medicamento mais adequado e qual o melhor \\
laboratório é o médico e não o farmacêutico \\
\hline UMA SOLUÇÃO \\
I M onopolização da produção de medicamentos pelo Estado
\end{tabular}

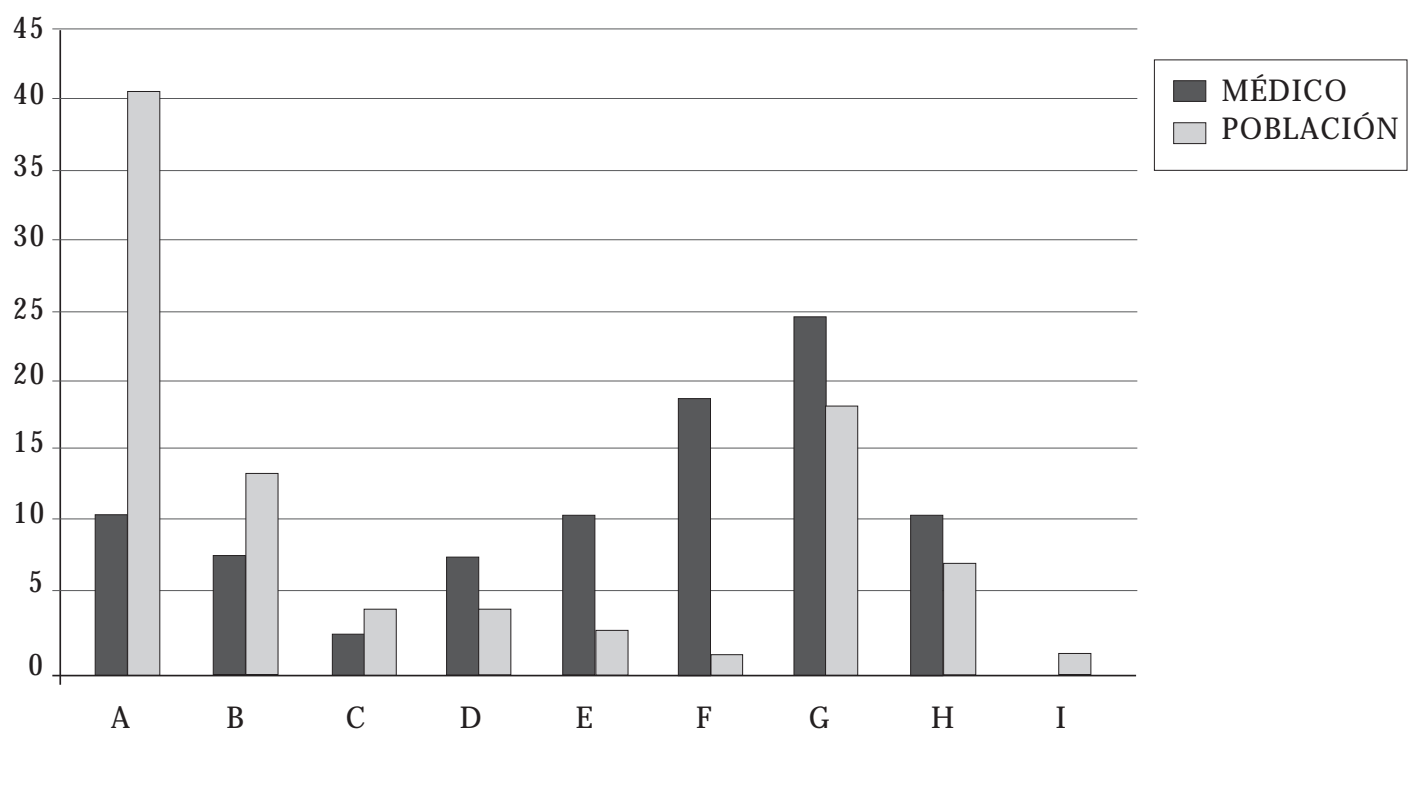

Gráfico 1. Representações sociais de médicos e da população sobre a relação entre preço e qualidade dos medicamentos. Buenos Aires, 2002. 
Vamos apresentar os discursos do sujeito coletivo correspondentes à representação $A$ : "Porque osmedicamentos podem ter preços diferentes, uma vez que o preço é determinado por vários fatores que não têm necessariamente a ver com a qualidade do medicamento", que nos mostram o argumento central dos discursos emitidos pelosindivíduos entrevistados, quando analisados, primeiro em conjunto e depois separadamente.

DSC A

Porque os medicamentos podem ter preços diferentes, uma vez que o preço é determinado por vários fatores que não têm necessariamente a ver com a qualidade do medicamento

(Porque los medicamentos pueden tener precios diferentes, una vez que el precio es determinado por varios factores que no tienen necesariamente a ver con la calidad del medicamento)

\section{M édicos e população}

Sim, creio que sim, que podem ter a mesma qualidade ou o mesmo efeito: são variados mas se podem ser diferentes no peso, podem no entanto ter a mesma qualidade; sai mas barato mas é a mesma coisa, acho, produzem a mesma ação estes dois remédios iguais

0 preço não é um indicador de qualidade. $A$ crença habitual éque maior preço, maior qualidade. Isto, no entanto, em muitos casos, é um engano; por exemplo, empresas que têm uma boa marca estabelecida abusam da imagem de marca para posicionar-se com um preço mais alto e estão oferecendo, do ponto de vista da efetividade básica, exatamente o mesmo que outros remédios de preço mais baixo.

Seguramente há medicamentos que, pela marca ou pela antiguidade, ou pelo que seja, têm preços mais caros que outros medicamentos que são novos no mercado e que podem entrar com preços mais econômicos. 0 queaconteceéquehá um aumento desmedido do preço nas grandes empresas devido ao empacotamento, o marketing; então, acredito que se pode conseguir remédios mais baratos com menos inversão. Há laboratórios que fazem investigação mas que têm preços excessivos; ainda utilizando a mesma monodroga, há muita diferença de preços.

Coloco um exemplo claro: 0 doce de leite. Há um doce de leite de uma determinada marca e há doces de leite de outras marcas, mas que são elaborados pela mesma fábrica e pelo simples fato de ter um nome, uma marca, saem duas a três vezes mais caro, mas é o mesmo doce de leite, tem 0 mesmo gosto e produz a mesma necessidade e, então, por isso mesmo é que considero que sim, que os medicamentos podem ser de preços diferentes e marcas diferentes e origens distintas e podem servir para a mesma coisa, sim podem servir.

Em uma palavra, é o mesmo medicamento: não tenha medo de tomá-lo.

\section{Médicos y población}

$\mathrm{Si}$, creo que si, que pueden tener la misma calidad o el mismo efecto: son variables pero se pueden ser diferentes en peso sin embargo tener de la misma calidad, sale más barato pero es lo mismo, qué se yo, hace la misma acción, estos dos remedios iguales.

El precio no es un indicador de calidad. La creencia habitual es a mayor precio mayor calidad. Sin embargo en muchos casos esto es engañoso, por ejemplo empresas que tienen una buena marca establecida, abusan de la imagen de marca para posicionarse en un precio alto y están ofreciendo, desde el punto de vista de la efectividad básica, exactamentelo mismo que otros de precio más bajo.

Seguramentehay medicamentos que por la marca o por la antigüedad, o por lo que sea, se los cobra mucho más caros que otros medicamentos que son nuevos en el mercado y pudieron entrar con precios más económicos. Lo que pasas es que hay un aumento desmedido del precio en las grandes empresas por el packaging, el marketing entonces creo que se pue de conseguir drogas más baratas con menos inversión. Hay laboratorios que hacen investigación pero que tienen precios excesivos, aun utilizando la misma monodroga hay mucha diferencia de precios.

Le pongo un ejemplo claro: el dulcedeleche. Hay un dulce de leche de cierta marca y hay dulce de leche de otras marcas pero que son elaborados por la misma fábrica y por el sólo hecho de tener un nombre, una marca, salen entre 2 ó 3 veces más caros, pero es el mismo dulce de leche, tieneel mismo gusto y produce la misma necesidad, y bueno, por eso mismo es por lo que considero sí que los medicamentos pueden ser de distinto precio y distinta marca y de distinto origen y pueden servir para lo mismo, y sí, pueden servir.

En una palabra: es la misma droga, no tengas miedo de tomarla.

Pode-se observar agora as diferenças entre os estratos (médicos e população) quando os discursos são analisados isoladamente: vê-se com clareza que o discurso (favorável) da população é mais enfático que o discurso (também favorável) dos médicos. 
População

Seguramente há medicamentos que pela marca ou pela antiguidade, ou pelo que seja, têm preços mais caros que outros medicamentos que são novos no mercado e que podem entrar com pre ços mais econômicos.

0 preço não é um indicador de qualidade. $\mathrm{A}$ crença habitual éque maior preço, maior qualidade. Isto, no entanto, em muitos casos é um engano, por exemplo, empresas que têm uma boa marca estabelecida abusam da imagem de marca para posicionar-se com um preço mais alto e estão ofe recendo, do ponto de vista da efetividade básica, exatamente o mesmo que outros remédios de pre ço mais baixo.

Então sim, tranquilamente, os remédios podem ter a mesma qualidade: são variados no peso, mas da mesma qualidade: estamos falando da mesma droga si, o resto é estrutura e demais coisas que se pagam einclusive subornos aos médicos (há muitíssimos subornos aos médicos).

Existem também laboratórios que fazem pesquisa, mas que têm preços excessivos: ainda utilizando a mesma monodroga, há muita diferença de preço. Coloco um exemplo claro: 0 doce de leite. Háum doce deleitede uma determinada marca e há doces de leite de outras marcas, mas que são elaborados pela mesma fábrica e pelo simples fato de ter um nome, uma marca, saem duas a três vezes mais caro, mas é o mesmo doce de leite, tem o mesmo gosto e produz a mesma necessidade e, então, por isso mesmo é que considero que sim, que os medicamentos podem ser de preços diferentes e marcas diferentes e origens distintas e podem servir para a mesma coisa, sim podem servir.

\section{Médicos}

Sim, creio que sim, que podem ter a mesma qualidade. 0 que acontece é que há um aumento desmedido do preço nas grandes empresas pelo empacotamento, pelo marketing; então; acredito que se pode conseguir remédios mais baratos com menos inversão.

De fato, há medicamentos de diferentes laboratórios, tanto nacionais quanto internacionais, que têm variações nos preços e a qualidade, em princípio, é a mesma porque clinicamente perce be-se que é a mesma.

Tudo depende da experiência pessoal, quer dizer, há laboratórios quetêm a droga original e temse que pagar pela marca assim como pagamos a marca de um jeans ou a marca de outra coisa.

Sabemos positivamente que, por sua vez, ou- tros laboratórios compram a droga para fabricála, ou seja, quea diferença de preços às vezes não se justifica.

\section{Población}

Seguramentehay medicamentos que por la marca o por la antigüedad, o por lo que sea, se los cobra mucho más caros que otros medicamentos que son nuevos en el mercado y pudieron entrar con precios más económicos.

Así, el precio no es un indicador de calidad. La creencia habitual es a mayor precio mayor calidad. Sin embargo en muchos casos esto es engañoso, por ejemplo empresas que tienen una buena marca establecida, abusan de la imagen de marca para posicionarse en un precio alto y están ofreciendo, desde el punto de vista de la efectividad básica exactamente lo mismo que otros de precio más bajo.

Entonces si, tranquilamente, los remedios pueden tener la misma calidad: son variables en peso pero de la misma calidad; estamos hablando de la misma droga si, el resto es estructura y demás cosas que se pagan e incluso sobornos a los médicos ( hay muchísimos sobornos a los médicos).

Hay también laboratorios que hacen investigación pero que tienen precios excesivos, aun utilizando la misma monodroga hay mucha diferencia de precio.

Lepongo un ejemplo claro: el dulce deleche. Hay un dulce de leche de cierta marca y hay dulce de leche de otras marcas pero que son elaborados por la misma fábrica y por el sólo hecho de tener un nombre, una marca, salen entre 2 ó 3 veces más caros, pero es el mismo dulce de leche, tiene el mismo gusto y produce la misma necesidad.

Por eso mismo es por lo que considero sí que los medicamentos pueden ser de distinto precio y distinta marca y de distinto origen y pueden servir para lo mismo, y sí, pueden servir.

\section{M édicos}

$\mathrm{Si}$, creo que si que pueden tener la misma calidad. Lo que pasas es quehay un aumento desmedido del precio en las grandes empresas por el packaging, el marketing entonces creo que se puede conseguir drogas más baratas con menos inversión.

Dehecho hay medicamentos de distintos laboratorios, tanto nacionales como internacionales que tienen variaciones en los preciosy la calidad, en principio, es la misma porque clínicamente uno lo veque esla misma.

Todo dependedela experiencia personal, es decir, hay laboratorios que tienen la droga original y uno 
tienequepagar la marca así como pagamos la marca de un jean o la marca de otra cosa.

Sabemos positivamente que a su vez otros laboratorios compran la droga para fabricarla o sea que la diferencia de precios a veces no se justifica.

Estes resultados ilustram, a nosso ver, alguns elementos aqui discutidos da temática da complexidade na medida em que revelam:

. como a pesquisa com o DSC pode gerar um painel deopiniões coletivas que, em conjunto eisoladamente, apresentam alta densidade semântica;

- como uma mesma opinião adquire matizes distintos na medida em que é gerada por atores sociais distintos (no caso, médicos e pacientes);

- como resultados qualitativos (os discursos) e quantitativos podem se articular;

. como a empiria por si só pode, numa larga medida, se auto-explicar.

\section{Conclusão}

O DSC pode ser visto como um conjunto de artifícios destinados a permitir queo pensamento coletivo, enquanto realidade empírica, se auto-expresse, ou, usando o referencial da teoria da complexidade, se auto-organize, viabilizando o resgate etrazendo à luz do dia as representações sociais sob a forma de discursos instituintes de sujeitos coletivos.
Assim, entendendo-se, da perspectiva da semiótica, o "grau zero" do pensamento das coletividades como objeto do signo, referente ou virtualidade, os discursos do sujeito coletivo, por serem depoimentos coletivos, aparecem como explicações descritivas deste referente que, assim, podem dialogar com o metadiscurso térico, que veicula explicações interpretativas do mesmo referente, além de poderem também - mas isso exigiria por certo uma discussão à parte que não cabeneste espaço "trialogarem" 15 com outros modos ou modalidades de explicação descritiva como as que decorrem de outras técnicas de geração de dados, como pesquisa documental, a observação participante, a abordagem etnográfica e outras.

No campo da saúde (e, é claro, também fora dele), resultados inesperados deste diálogo ou "triálogo" de explicações entre discurso emetadiscurso propiciado pelo DSC podem surgir, opondo, dialeticamente, sujeitos portadores de metadiscursos e sujeitos portadores de discursos, ou seja, ciência (metadiscurso científico) esenso comum (discurso do senso comum), perspectiva técnica eperspectiva leiga, médico e paciente ${ }^{16}$, usuário de serviço eprofissional, consumidor e sujeito de direito e tantas outras oposições ou contradições, propiciando a emergência da complexidade sob a forma de sínteses inéditas desta tensão epistemológica e sociológica que apontem para o diferente e, consequentemente, para a transformação social.

\section{Colaboradores}

Lefevre F, Lefevre AMC e M arques M CC participaram igualmente de todas as etapas de elaboração do artigo. 


\section{Referências}

1. Lefevre F, Lefevre AMC. D epoimentos e discursos. Brasília: Liberlivro; 2005.

2. Peirce CS. Semiótica e filosofia. São Paulo: Cultrix/ Edusp; 1975.

3. Aleksandrowicz AMC. Complexidade e metodologia: um refinado retorno às fronteiras do conhecimento. In: M inayo MCS, Deslandes SF, organizadoras. Caminhos do pensamento: epistemologia e método. Rio de Janeiro: Fiocruz; 2003. p. 49-79.

4. Ardoino J. Educação e Complexidade. Diálogo com Jacques Ardoino. In: Morin E, Le Moigne J-L. A inteligência da complexidade. São Paulo: Peirópolis; 1999. p. 171-195.

5. Silva JM. Em busca da complexidade esquecida. Revista FAM ECOS 1996; 5:14-20.

6. Atlan H. DNA: Programa ou dados? In: M orin E, organizador. A religação dos saberes: 0 desafio do século XXI. Rio de Janeiro: Bertrand Brasil; 2002. p. 157-171.

7. Parreira A. A Diversidade européia e o paradigma da complexidade. Revista Lusófona de Ciência Política e Relações Internacionais 2005; 1:15-22.

8. Jodelet $D$. Representations sociales: un domaine en expansion. In: Jodelet $\mathrm{D}$, editeur. Representations sociales. Paris: Puf; 1989.

9. Bourdieu P. Coisas ditas. São Paulo: Brasiliense; 1990.

10. Prefeitura de Itapecerica da Serra. Relatório de gestão. Itapecerica da Serra: Prefeitura de Itapecerica da Serra; 2000.
11. Lefevre F, Lefevre AMC. 0 que é vigilância á saúde? Representação dos funcionários do CVE. São Paulo: FSP/ USP; 2004.

12. Althusser L. Dialética e Ciências Sociais. Rio de Janeiro: Zahar; 1967.

13. Bourdieu P, Passeron JC. La reproduction: elements pour une theorie du systeme d'enseignement. Paris: M inuit; 1970.

14. Lefevre F, Lefevre AMC. Recuperando a fala do social. São Paulo: USP/FSP/HSP; 1998.

15. M inayo MCS, Assis SG, Souza ER, organizadores. Avaliação por triangulação de métodos: abordagens de programas sociais. Rio de Janeiro: Fiocruz; 2005.

16. Silva WM. Navegar é preciso.Avaliação de impactos do uso da internet na relação médico-paciente [dissertação]. São Paulo (SP): Faculdade de Saúde Pública, USP; 2006.

Artigo apresentado em 01/11/2006

Aprovado em 26/02/2007

Versão final apresentada em 05/04/2007 